\title{
Effect of additives on hydration and hardening of magnesia compositions
}

\author{
Olga Miryuk* \\ Rudny Industrial Institute, Republic of Kazakhstan
}

\begin{abstract}
The article is devoted to the investigation of the influence of technological factors on the hydration and hardening of magnesia compositions. The objective - is investigation magnesia compositions with different additives. Factors which impact activity of magnesium oxide in compositions of different structure are investigated. Influence of liquid density on hardening of magnesium bindings is defined. Processes of hydration and hardening of magnesium bindings with participation of minerals - silicates are investigated. It is revealed that the addition of semiaquatic calcium sulfate contributes to the hardening of magnesia binders. Defined effect of concentration calcium sulfate hemihydrate to the hardening of caustic magnesite. Here are proposed structures of sulphomagnesium compositions containing technogenic components. It revealed a beneficial effect on the hardening of ferrous component of the mixed magnesia binder. Composition of hydration products of magnesium binding with participation of ferriferous minerals is presented. Transformations of phases at hydration of magnesium binding are revealed. Influence of structure of bindings on transformations of hydrates is established. Results of research of magnesia bindings of long hardening are given. It is shown that the durability of stone of bindings is provided with dense structure of hydrates. In researches are used X - Ray and thermal methods, electronic microscopy.
\end{abstract}

\section{Introduction}

Magnesia binders reveal activate capacity in relation for various materials. This became background for getting mixed binders from caustic magnesite and mineral component $[1-7]$. The combination of caustic magnesite of natural and technogenic materials expands the range and increased the volume of magnesia binders. Magnesia compositions characterized by low energy intensity of production, intensive hardening and high strength. Containing of magnesium component in the composition of mixed binders is $50-70 \%$. Recourses of magnesia rocks are limited. It is necessary to reduce deficit caustic magnesite in the composition with mixed binders. The advantages of mixed binders are to improve the physical and mechanical properties while saving caustic magnesite and rational use of natural and technogenic raw materials. The purpose of the work is synthesis and investigation magnesia compositions with different additives.

\footnotetext{
* Corresponding author: psm58@mail.ru
} 


\section{Methodology}

For experiments were used: caustic magnesite mark PMK - 75, building gypsum mark $\mathrm{G}$ - 5AII, minerals from geological collections, technogenic materials. In the experiments used minerals that are predominant in the composition of the studied technogenic materials (wastes from enrichment of skarn-magnetite ores, screening of granodiorite crushing, wastes from extraction of gold-copper ores, screening of plagioclase crushing, slag metallurgical).

Binding compositions were prepared by thoroughly mixing fine components. Strength properties were determined on samples with size 20x20x20 mm, made with dough of normal density. Magnesia composition hardened in air and in a humid environment, taking into account the objectives of the experiment.

The phase composition of the materials was determined using general purpose $\mathrm{X}$-ray diffractometer type DRON-3M. The diffractometer is equipped with an BSV-24 type $\mathrm{X}$-ray tube with $\mathrm{CuK} \alpha$-radiation. The diffractograms were processed using the difWin program. Thermochemical processes were studied by the differential thermal analysis method, which was carried out on a derivatograph of the «MOM» firm of the F.Paulik, I.Paulik and L.Erdey systems. The structure of the compositions was investigated using a JSM - 649OLV Energy scanning electron microscope.

\section{Results and discussions}

Structure of magnesium binders is unique by presence of magnesium oxide, which in comparison with calcium oxide is slightly soluble and slowly reacts with water. This is $[2,4]$ due to skinning effect $\mathrm{Mg}(\mathrm{OH})_{2}$, which is prevent from water penetration into deep into the grain binder. Hardenings of magnesia materials, mixing with water, do not have much practical value.

With the introduction of salt (chloride or magnesium sulfate), into hardener significantly increased solubility of magnesium oxide, increases degree of supersaturation and accelerates the crystallization of brucite, forms hydro oxide salt.

Magnesia binders, mixing a solution of magnesium chloride hardens rapidly, are highly durable. Caustic magnesite, coupled with a solution of magnesium chloride activates siliceous, aluminosilicate and other substances. This capability is implemented in the magnesium binder compositions using natural and anthropogenic materials. Activity of $\mathrm{MgO}$ in compositions depends on many factors. The nature of these factors requires clarification.

\subsection{Activity of magnesium oxide in magnesium compositions}

The influence of the type of the liquid component on the hydration of the magnesia binder was investigated. The nature of changes in the content of basic hydrates was determined by the intensity (height) of the main diffraction reflections of hydrates using $\mathrm{X}$ - ray analys (Fig. 1). Increasing density of solution $\mathrm{MgCl}_{2}$ in the limits $1150-1400 \mathrm{~kg} / \mathrm{m}^{3}$ for caustic magnesite limits or fully exclude formation of $\mathrm{Mg}(\mathrm{OH})_{2}$; provides growth of containing magnesium pentahydrate oxychloride $5 \mathrm{Mg}(\mathrm{OH})_{2} \cdot \mathrm{MgCl}_{2} \cdot 8 \mathrm{H}_{2} \mathrm{O}$ ( $\ll 5$ - form»), which is prevail in the composition of crystalline hydrate using solution with density $1250-1400$ $\mathrm{kg} / \mathrm{m}^{3}$ (Fig. 1). A large proportion of the $« 5-$ form» is formed in the early stages, providing a high rate of hardening stone.

As part of a binder, mixing solutions of high density $\left(1350\right.$ and $\left.1400 \mathrm{~kg} / \mathrm{m}^{3}\right)$, identified hydrated complex $3 \mathrm{Mg}(\mathrm{OH})_{2} \cdot \mathrm{MgCl}_{2} \cdot 8 \mathrm{H}_{2} \mathrm{O}$ ( $\ll 3$ - form») - magnesium trihydrate oxychloride. Hydrate « 3 - form» is formed by recrystallization of a small part of 
«5 - form». There is no clear relationship between the concentration of $\mathrm{MgCl}_{2}$ solution, and the degree of hydration of $\mathrm{MgO}$. This indicates the dependence of activity $\mathrm{MgO}$ from content and structure of hydrates.

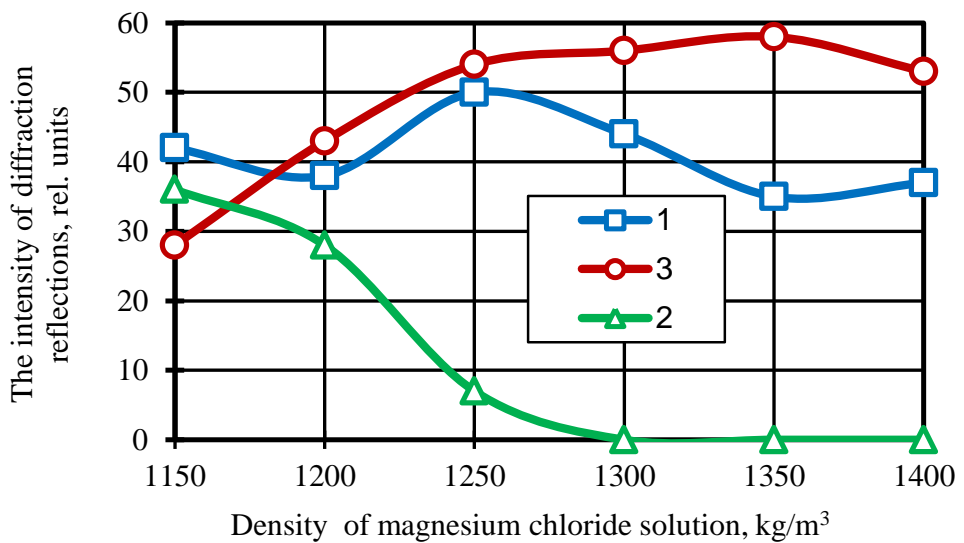

Fig. 1. Influence of sealer density on phase composition and strength of caustic magnesite stone (7 days): $1-\mathrm{MgO} ; 2-\mathrm{Mg}(\mathrm{OH})_{2} ; 3-5 \mathrm{Mg}(\mathrm{OH})_{2} \cdot \mathrm{MgCl}_{2} \cdot 8 \mathrm{H}_{2} \mathrm{O}$.

Along with salt solutions, magnesium binders are recommended to temper with acids solution $\mathrm{HCl}$ [7]. To obtain comparative characteristics was used $\mathrm{MgCl}_{2}$ solution with density of $1250 \mathrm{~kg} / \mathrm{m}^{3}$ and complex solution (solution of $\mathrm{MgCl}: \mathrm{HCl}: \mathrm{H}_{2} \mathrm{O}-2: 1: 1$, volumetric parts).

When tempering caustic magnesite with complex solution hydration level of $\mathrm{MgO}$ is increased on $6 \%$. In the cured binder is formed $\operatorname{Mg}(\mathrm{OH})_{2}$. A content of magnesium pentahydrate oxychloride reduces on $28 \%$, which is lead to decreasing strength of the stone. Staying in the water samples twice reduces the proportion of the initial $\mathrm{MgO}$; provides a significant increase quantity of $\mathrm{Mg}(\mathrm{OH})_{2}$. There is a part of hydrate $5 \mathrm{Mg}(\mathrm{OH})_{2} \cdot \mathrm{MgCl}_{2} \cdot 8 \mathrm{H}_{2} \mathrm{O}$ in the water.

According to the $\mathrm{X}$ - ray analysis, in the stone, which was hardened 28 days, save up to $30 \%$ uncombined $\mathrm{MgO}$.

The tendency of growth activity of $\mathrm{MgO}$ and increasing the degree of its transformation into hydrate oxychloride complexes safes when added to the caustic magnesite mineral component. Character of hydrate formation with participation $\mathrm{MgO}$ also depends on the composition of the mineral component. These approve results of investigations binders of caustic magnesite $(35 \%)$ and minerals - silicates $(65 \%)$, tempered with solution of magnesium chloride with density $1220 \mathrm{~kg} / \mathrm{m}^{3}$ (Table 1 ).

The highest degree of conversion of magnesium oxide is characteristic for compositions containing silicates insular structure (andradite and epidote), which are more prone to hydrolytic decomposition in a solution of magnesium chloride.

Another indication of the influence of material composition on hydration activity of magnesium oxide and the composition of hydrates is the nature of phases changes in mixtures $\mathrm{MgO}$ with $\mathrm{Al}_{2} \mathrm{O}_{3}$ and $\mathrm{SiO}_{2}$ (additive content $45 \%$ ). Ratio of diffraction intensity reflections of magnesium oxide for binders consisting of $\mathrm{MgO}, \ll \mathrm{MgO}+\mathrm{Al}_{2} \mathrm{O}_{3} », \ll \mathrm{MgO}+$ $\mathrm{SiO}_{2} »$, respectively, equal to $1: 0.5: 0.3$; the diffraction reflections of magnesium pentahydrate oxychloride $-1: 3.6: 4.3$.

Important indicator of phase activity is hydration with prolong hardening. Here are investigated mixed binders, tempered with solution $\mathrm{MgCl}_{2}$ with density $1250 \mathrm{~kg} / \mathrm{m}^{3}$ and which were hardened in various mediums during 5 years. 
Table 1. Influence of minerals structure on phase content in hardened mixed magnesium binders.

\begin{tabular}{|l|c|c|c|c|c|c|}
\hline \multirow{3}{*}{ Mineral } & \multicolumn{6}{|c|}{ The intensity of the diffraction reflections of } \\
phases, rel. units
\end{tabular}

By the data of $\mathrm{X}$ - ray analysis, stone crystal foundation of air hardening are form hydrate oxychloride complexes, formed on initial stages of hydration. Presence of $20 \%$ free $\mathrm{MgO}$ indicates on not full realization binding properties of component. This can serve as recourse for further hydro formation. In the stone of water hardening saves up to $5-10 \%$ of initial $\mathrm{MgO}$; contains $\mathrm{Mg}(\mathrm{OH})_{2}$, formed by the decay of a significant amount of hydrates.

Replacement of magnesium chloride by complex temper (solution $\mathrm{MgCl}_{2}: \mathrm{HCl}: \mathrm{H}_{2} \mathrm{O}-$ $2: 1: 1$, volumetric parts) for the mixed binder is accompanied by a slight slowing of the hydration $\mathrm{MgO}$ in the initial period of hardening; formation of $\mathrm{Mg}(\mathrm{OH})_{2}$ in the stone of binder; formation hydrate oxychloride complexes in amounts comparable with the content of these phases in the composition, tempered with $\mathrm{MgCl}_{2}$ solution. Staying samples of hardened binder in water accelerates the hydration of $\mathrm{MgO}$ and helps to complete the process to 28 days of hardening. As part of the stone increases number of $\mathrm{Mg}(\mathrm{OH})_{2}$ and reduced the proportion of $5 \mathrm{Mg}(\mathrm{OH})_{2} \cdot \mathrm{MgCl}_{2} \cdot 8 \mathrm{H}_{2} \mathrm{O}$.

With complete elimination of magnesium chloride from the structure of temper and use of hydrochloric acid solution with density $1050 \mathrm{~kg} / \mathrm{m}^{3}$ hydration activity of magnesium oxide is changed slightly. In this case $\mathrm{MgO}$ in the mixed binders also differs by high speed of hydration. Strength values of samples based on $\mathrm{HCl}$ solution are reduced nearly threefold compared with salt temper. However, staying samples in water within 60 days provided the increase of strength on $40 \%$ compared with similar samples of air hardening. Hardening of the stone in the water promoted complete hydration and participation of $\mathrm{MgO}$ in the formation of hydromagnesium. This confirms the reduction intensity of the diffraction reflections of minerals and invariability of reflexes $\mathrm{Mg}(\mathrm{OH})_{2}$ on diffraction patterns of binder with various degrees of hydration of $\mathrm{MgO}$.

Therefore, changing the recipe of magnesia binders allows you to adjust the type and amount of hydrates, affect the construction and technical properties and durability of materials. The greatest increase in the hydration activity of magnesium oxide in magnesia compositions is achieved by the addition of minerals. It has been revealed that according to the degree of participation in hydration processes, comprising $25-60 \%$, the minerals silicates are located in the series: albite $\rightarrow$ epidote $\rightarrow$ andradite $\rightarrow$ diopside. The effect of minerals is as follows: an increase in the degree of conversion of $\mathrm{MgO}$ to magnesium hydroxychlorides; minimization of $\mathrm{Mg}(\mathrm{OH})_{2}$; predominance of $5 \mathrm{Mg}(\mathrm{OH})_{2} \cdot \mathrm{MgCl}_{2} \cdot 8 \mathrm{H}_{2} \mathrm{O}$.

Purposeful selection of a salt solution for magnesia compositions provides an increase in the degree of hydration of magnesium oxide, the formation of hydrates, more resistant to exposure to the aquatic environment. 


\subsection{Investigation of sulfomagnesium compositions}

The advantage of adding calcium sulfate to magnesia binder is mentioned in work [5]. For optimization the concentration of gypsum component investigated series of compositions «caustic magnesite - semi-aquatic calcium sulfate», tempered by solution of $\mathrm{MgCl}_{2}$.

With the introduction semi-aquatic calcium sulfate reduced water demand, prolonged time of setting binder. Replacement to $60 \%$ of caustic magnesite semi-calcium sulfate does not reduce the strength of the compositions, which in some cases exceed the benchmark on 25\% (Fig. 2). Hardening of sulfomagnesium binder takes place at the initial hydration of $\mathrm{MgO}$. Activity $\mathrm{MgO}$ rises with increasing of gypsum component. In the structure of hydrates dominated $5 \mathrm{Mg}(\mathrm{OH})_{2} \cdot \mathrm{MgCl}_{2} \cdot 8 \mathrm{H}_{2} \mathrm{O}$. In low magnesium binders also formed $\mathrm{Mg}(\mathrm{OH})_{2} \cdot \mathrm{MgCl}_{2} \cdot 2 \mathrm{MgCO}_{3} \cdot 6 \mathrm{H}_{2} \mathrm{O}$.

Hardening sulfomagnesium binders is occur in initial hydration of magnesium oxide, which activity rises with increasing portion of building plaster (Table 2). The highest degree of hydration of $\mathrm{MgO}$ is typical for the first 7 days, later reactive ability of phase reduced. Effect of temper concentration on the activity of $\mathrm{MgO}$ sulfomagnesium binders is inexpressively. In the structure of new formations is prevail $5 \mathrm{Mg}(\mathrm{OH})_{2} \cdot \mathrm{MgCl}_{2} \cdot 8 \mathrm{H}_{2} \mathrm{O}$. With In the process of hydration of binders with a low content of the magnesia component a complex carbonate-containing hydrate $\mathrm{Mg}(\mathrm{OH})_{2} \cdot \mathrm{MgCl}_{2} \cdot 2 \mathrm{MgCO}_{3} \cdot 6 \mathrm{H}_{2} \mathrm{O}$ is formed. Intensive formation of magnesium hydrate complexes provides high strong characteristics of sulfomagnesium binder.

High values of hydration activity and strength of sulfomagnesium binder let use it as an activator of hardening. Were investigated compositions based on sulfomagnesium binder and anthropogenic materials in the component ratio $50: 50 \%$. As temper were used magnesium chloride and sulphate solutions with density $1250 \mathrm{~kg} / \mathrm{m}^{3}$. Caustic magnesite was a control composition.

The introduction of technogenic component reduces the volume of solution on $32-37 \%$ compared with the caustic magnesite.

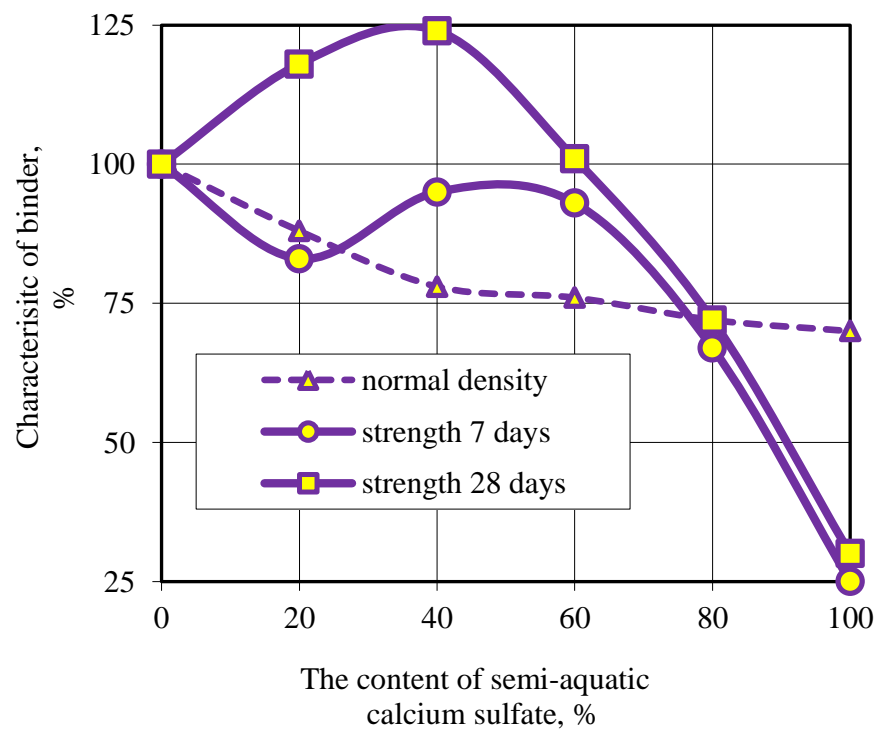

Fig. 2. Influence of semiaquatic calcium sulfate on properties sulfomagnesium composition. 
Table 2. Containing phases in the hardened sulfomagnesium binder $\left(40 \% \mathrm{CaSO}_{4} \cdot 0,5 \mathrm{H}_{2} \mathrm{O}\right)$.

\begin{tabular}{|c|c|c|c|}
\hline \multirow{2}{*}{$\begin{array}{c}\text { Density } \\
\text { of solution } \mathrm{MgCl}_{2}, \\
\mathrm{~kg} / \mathrm{m}^{3}\end{array}$} & \multirow[t]{2}{*}{ Age, days } & \multicolumn{2}{|c|}{$\begin{array}{c}\text { The intensity } \\
\text { of the reflection phase } \\
\text { in the diffraction } \\
\text { pattern, relation of units }\end{array}$} \\
\hline & & $\begin{array}{c}\text { MgO } \\
(0.148 \text { nm) }\end{array}$ & $\begin{array}{l}\text { «5 - form». } \\
(0.196 \mathrm{~nm})\end{array}$ \\
\hline 1240 & 1 & 102 & 190 \\
\hline 1240 & 90 & 90 & 185 \\
\hline 1200 & 7 & 98 & 165 \\
\hline 1240 & 7 & 96 & 210 \\
\hline 1280 & 7 & 97 & 260 \\
\hline
\end{tabular}

The greatest influence on the hardening mixed binders has composition of salt solution. The use of $\mathrm{MgCl}_{2}$ solution provides increased hydration activity $\mathrm{MgO}$, contributes to the intense stone hardening and increases its strength on $12-70 \%$. The high strength characteristics of three-component binders - is the result of a joint magnesium chloride and sulfate activation of hardening anthropogenic material. Activity of technogenic component depends on the structure and chemical properties of minerals. The greatest strength is achieved with the introduction of wastes from enrichment of skarn-magnetite ores and screening of plagioclase crushing.

\subsection{Hardening of magnesia compositions containing ferrous component}

The range of the magnesia cement extends at the expense of compositions from the caustic magnesite and filler. Preference of ferriferous by-product additives in the magnesia cement is noted $[7,10]$.

For receiving the binding materials used the caustic magnesite, chemical reactants, and natural minerals. Binding materials added water to a mix of magnesium chloride. Phase structure of the hardened compositions was estimated by $\mathrm{X}$ - ray and differential thermal methods. Stone structure of the binding materials was investigated by the means of electronic microscopy.

Nature of curing of binding materials depends on the maintenance of $\mathrm{MgO}$. The analysis of diffraction patterns revealed that with increase in a share of $\mathrm{Fe}_{2} \mathrm{O}_{3} \mathrm{MgO}$ hydration is accelerated. In comparison with binding materials, which containing $\mathrm{SiO}_{2}$ and $\mathrm{Al}_{2} \mathrm{O}_{3}$, in composition the $\mathrm{Fe}_{2} \mathrm{O}_{3}$ hyperactivity of $\mathrm{MgO}$. The extent of transformation of $\mathrm{Fe}_{2} \mathrm{O}_{3}$ in hydrates $5-18 \%$. Basis of the hardened binding materials forms $5 \mathrm{Mg}(\mathrm{OH})_{2} \cdot \mathrm{MgCl}_{2} \cdot 8 \mathrm{H}_{2} \mathrm{O}$. Place the figure as close as possible after the point where it is first referenced in the text. If there is a large number of figures and tables it might be necessary to place some before their text citation.

Pyrites $\mathrm{Fe}\left[\mathrm{S}_{2}\right]$ - the widespread sulfide of crust. Possibility of introduction $70 \%$ of pyrites in magnesium knitting is proved. As a part crystalline hydrates prevails $5 \mathrm{Mg}(\mathrm{OH})_{2} \cdot \mathrm{MgCl}_{2} \cdot 8 \mathrm{H}_{2} \mathrm{O} .40-60 \%$ of pyrites are involved in hydrate formation of the binding materials. Processes of hydrolysis and the oxidations of pyrites accelerated in $\mathrm{MgCl}_{2}$ solution are presented by the scheme:

$$
\left(\mathrm{Fe}^{2+}+\mathrm{S}_{2}{ }^{2-}\right)+3\left(\mathrm{H}^{+}+\mathrm{OH}^{-}\right)+4 \mathrm{O}_{2} \rightarrow \mathrm{Fe}(\mathrm{OH})_{3}+2\left(\mathrm{SO}_{4}{ }^{2-}\right)+3 \mathrm{H}^{+} .
$$

Exothermic effect at $550^{\circ} \mathrm{C}$ characterizes oxidation of pyrites (Fig. 3). Pentahydroxichloride of magnesium remains in composition of long-term curing. The microconglomerate structure of a stone from particles of various morphology promotes consolidation and increase of stability of structure to destructive processes (Fig. 4). 


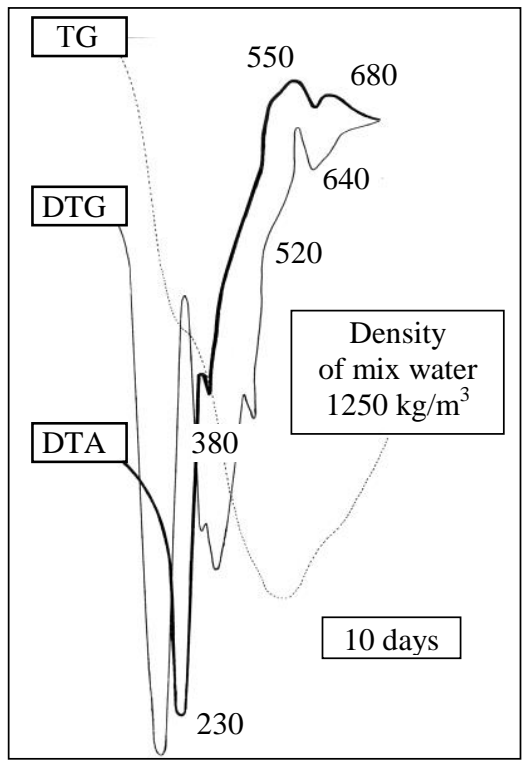

Fig. 3. Thermogram of magnesium composition stone with $70 \%$ of pyrites.

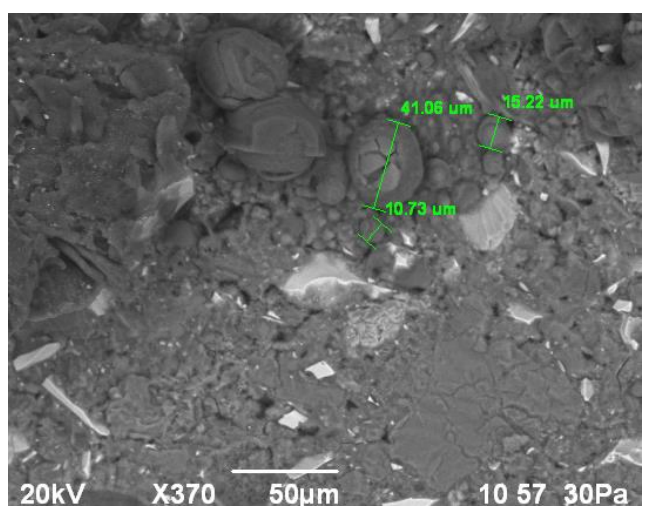

Fig. 4. Microstructure of magnesium composition stone with $70 \%$ of pyrites after 10 years curing.

Andradite $\mathrm{Ca}_{3} \mathrm{Fe}_{2}\left[\mathrm{SiO}_{4}\right]_{3}$ - the widespread scans mineral, provides stable curing of the binding materials. Compositions from $30-60 \%$ of andradite are investigated. The main hydrate phase is $5 \mathrm{Mg}(\mathrm{OH})_{2} \cdot \mathrm{MgCl}_{2} \cdot 8 \mathrm{H}_{2} \mathrm{O}$.

General scheme of probable transformation of andradite:

$\mathrm{Ca}_{3} \mathrm{Fe}_{2}\left(\mathrm{SiO}_{4}\right)_{3}+n \mathrm{Mg}^{2+}+(4 x+1) \mathrm{H}_{2} \mathrm{O} \rightarrow \mathrm{Ca}_{3} \mathrm{Fe}_{2}\left(\mathrm{SiO}_{4}\right)_{3-x}(\mathrm{OH})_{4 x}+n \mathrm{MgO} \cdot x \mathrm{SiO}_{2} \cdot \mathrm{H}_{2} \mathrm{O}$.

Hydrate of $\mathrm{Mg}(\mathrm{OH})_{2} \cdot \mathrm{MgCl}_{2} \cdot 2 \mathrm{MgCO}_{3} \cdot 6 \mathrm{H}_{2} \mathrm{O}$ is formed after 1 days of curing. Intensive formation of hydro-oxchloride carbonate magnesium is promoted the increase in a ratio of $\mathrm{MgCl}_{2}: \mathrm{MgO}$ in the binding materials. The extent of andradite transformation in the hydrates, defined by $\mathrm{X}$ - ray method, was made $20-23 \%$ for 7 days.

Therefore, magnesium compositions, containing pyrites are characterized by high hydration ability, the formation of hydrates, strengthening the structure of materials.

High strength properties of pyrites-containing binders are provided by the activating effect of sulfate-ions on the hydration ability of $\mathrm{MgO}$; optimization of the ratio of crystalline and amorphous hydrates. 


\section{Conclusions}

For the first time magnesia compositions, containing minerals, present in technogenic materials, were studied. It has been established, that the introduction of minerals contributes to an increase in the activity of $\mathrm{MgO}$; the predominance of $5 \mathrm{Mg}(\mathrm{OH})_{2} \cdot \mathrm{MgCl}_{2} \cdot 8 \mathrm{H}_{2} \mathrm{O}$, which provides high strength properties of the stone; the formation of $\mathrm{Mg}(\mathrm{OH})_{2} \cdot \mathrm{MgCl}_{2} \cdot 2 \mathrm{MgCO}_{3} \cdot 6 \mathrm{H}_{2} \mathrm{O}$; competition in the formation of hydrate complexes.

It is shown, that a change in the composition and density of the salt solution enhances the effect of minerals on the hardening of magnesia compositions. The dependence of the composition, amount and stability of hydrates on the concentration of $\mathrm{MgO}$ and $\mathrm{MgCl}_{2}$, the type and activity of the mineral was determined.

Proved high reactivity of iron supplements for hardening magnesia compositions. The nature of the influence of minerals has been revealed, hydrate formation schemes have been proposed based on common technogenic wastes minerals (pyrites, andradite). Reactionary ability of a ferriferous component provides high activity of magnesium composition of oxychloride curing, variety of crystal and gel hydrates.

The possibility of obtaining magnesia compositions with a high content of calcium sulfate $(40-60 \%)$. Efficiency of sulfomagnesium compositions determined by the possibility of replacing part of caustic magnesite by gypsum binder and technogenic component, with saving high technical characteristics of material.

The development of mixed magnesia binders using technogenic wastes is aimed at expanding the resource base and increasing the durability of efficient building materials.

\section{References}

1. Z. Xiangming, L. Zongjin, Const. Build. Mat. 27, 382 (2012)

2. M. Jianli, Z. Youcai, W. Jinmei, W. Li, Const. Build. Mat. 24, 79 (2010)

3. D. Zhu, L. Zongjin, Cem. Conc. Comp. 27, 11 (2005)

4. V. N. Zyryanova, E.V. Lytkina, G.I. Berdov, Tech. Technol. Silic. 17, 2 (2010)

5. Z. Li, C. K. Chau, Cem. Conc. Comp. 37, 866 (2007)

6. K. Yildirim, M. Sümer, Comp. Eng. 52, 56 (2013)

7. O. A. Miryuk, ARPN J. Eng. Appl. Sciences, 13, 545 (2018) 